University of Wollongong

Research Online

Faculty of Engineering and Information

Faculty of Engineering and Information

Sciences - Papers: Part A

Sciences

2013

Modeling dense-phase pneumatic conveying of powders using suspension density

S S. Mallick

Thapar University, ssm672@uow.edu.au

P W. Wypych

University of Wollongong, wypych@uow.edu.au

R Pan

Fujian Longking Co

Follow this and additional works at: https://ro.uow.edu.au/eispapers

Part of the Engineering Commons, and the Science and Technology Studies Commons

Research Online is the open access institutional repository for the University of Wollongong. For further information contact the UOW Library: research-pubs@uow.edu.au 


\title{
Modeling dense-phase pneumatic conveying of powders using suspension density
}

\author{
Abstract \\ This article presents results of an investigation into the modeling of pressure drop in horizontal straight \\ pipe section for fluidized dense-phase pneumatic conveying of powders. Suspension density and \\ superficial air velocity have been used to model pressure drop for two-phase solids-gas flow. Two \\ applicable models formats (developed by other researchers using two different definitions of suspension \\ density) were used to represent the pressure drop due to solids-gas flow through straight pipe sections. \\ Models were generated based on the test data of conveying power-station fly ash and electrostatic \\ precipitator (ESP) dust (median particle diameter: 30 and $7 \mu \mathrm{m}$; particle density: 2300 and $3637 \mathrm{~kg} \mathrm{~m}-3$; \\ loose-poured bulk density: 700 and $610 \mathrm{~kg} \mathrm{~m}-3$, respectively) through a relatively short length of a smaller \\ diameter pipeline. The developed models were evaluated for their scale-up accuracy and stability by using \\ them to predict the total pipeline pressure drop (with appropriate bend model) for $69 \mathrm{~mm}$ I.D. $\times 168 \mathrm{~m}$; \\ $105 \mathrm{~mm}$ I.D. $\times 168 \mathrm{~m}$ and $69 \mathrm{~mm}$ I.D. $\times 554 \mathrm{~m}$ pipes and comparing the predicted versus with \\ experimental data. Results show that both the models with suspension density and air velocity generally \\ provide relatively better prediction compared to the conventional use of solids loading ratio and Froude \\ number. For fly ash, the two formats result in considerable different predictions, whereas they provide \\ relatively similar results for ESP dust.
}

\section{Keywords}

density, dense, suspension, modeling, powders, conveying, pneumatic, phase

\section{Disciplines}

Engineering | Science and Technology Studies

\section{Publication Details}

Mallick, S. S., Wypych, P. W. \& Pan, R. (2013). Modeling dense-phase pneumatic conveying of powders using suspension density. Particulate Science and Technology: an international journal, 31 (4), 340-347. 


\title{
Modeling Dense-Phase Pneumatic Conveying of Powders Using Suspension Density
}

\author{
S. S. MALLICK, ${ }^{1}$ P. W. WYPYCH, ${ }^{2}$ and R. PAN ${ }^{3}$ \\ ${ }^{1}$ Department of Mechanical Engineering, Thapar University, Patiala, Punjab, India \\ ${ }^{2}$ Faculty of Engineering, University of Wollongong, Wollongong, New South Wales, Australia \\ ${ }^{3}$ Fujian Longking Co., Ltd., Longyan, Fujian, P. R. China
}

This article presents results of an investigation into the modeling of pressure drop in horizontal straight pipe section for fluidized dense-phase pneumatic conveying of powders. Suspension density and superficial air velocity have been used to model pressure drop for two-phase solids-gas flow. Two applicable models formats (developed by other researchers using two different definitions of suspension density) were used to represent the pressure drop due to solids-gas flow through straight pipe sections. Models were generated based on the test data of conveying power-station fly ash and electrostatic precipitator (ESP) dust (median particle diameter: 30 and $7 \mu \mathrm{m}$; particle density: 2300 and $3637 \mathrm{~kg} \mathrm{~m}^{-3}$; loose-poured bulk density: 700 and $610 \mathrm{~kg} \mathrm{~m}^{-3}$, respectively) through a relatively short length of a smaller diameter pipeline. The developed models were evaluated for their scale-up accuracy and stability by using them to predict the total pipeline pressure drop (with appropriate bend model) for $69 \mathrm{~mm}$ I.D. $\times 168 \mathrm{~m}$; $105 \mathrm{~mm}$ I.D. $\times 168 \mathrm{~m}$ and $69 \mathrm{~mm}$ I.D. $\times 554 \mathrm{~m}$ pipes and comparing the predicted versus with experimental data. Results show that both the models with suspension density and air velocity generally provide relatively better prediction compared to the conventional use of solids loading ratio and Froude number. For fly ash, the two formats result in considerable different predictions, whereas they provide relatively similar results for ESP dust.

Keywords: Dense-phase, pneumatic conveying, pressure drop, suspension density

\section{Introduction}

Dense-phase pneumatic conveying of powders is gaining increasing popularity in different industries such as power (fly ash conveying), cement, chemical, pharmaceutical, alumina, limestone, and refinery due reduced transport gas flow requirement (resulting in lower sized compressor with substantial energy savings), smaller pipeline diameter and support structures, reduced wear rate of pipeline (especially in the bends), smaller sized gas-solids separation unit, and so on. While designing a pipeline system, it is important to reliably predict the total pipeline pressure drop. The loss of pressure for the flow of solids-gas mixture through a horizontal straight pipe section can be calculated using Equation (1) (Barth 1958).

$$
\Delta \mathrm{P}=\left(\lambda_{\mathrm{f}}+\mathrm{m} * \lambda_{\mathrm{s}}\right) \mathrm{L} / \mathrm{D} \rho \mathrm{V}^{2} / 2
$$

In Equation (1), the pressure drop components due to the flow of solids and air are treated and calculated separately. Weber (1981) considered this equation applicable only to coarse particles in dilute-phase flow. However, various researchers (Pan 1992; Pan and Wypych 1998; Jones and Williams; 2003; Williams and Jones 2004) used this relationship to predict the pressure loss for the dense-phase flow of

Address correspondence to: S. S. Mallick, Department of Mechanical Engineering, Thapar University, Patiala, Punjab147004, India. E-mail: ssmallick@thapar.edu fine powders, such as fly ash. Due to the highly complex and turbulent nature of the moving bed of powder, power function based empirical models have been employed over the years by various researchers, such as those listed above, to avoid the need to develop fundamental relationships between solids friction factor and the relevant particle and bulk properties. These power function models used different parameter groupings, as provided in Equations (2) and (3).

$$
\begin{gathered}
\lambda_{\mathrm{s}}=\mathrm{K}(\mathrm{m} *)^{\mathrm{a}}(\mathrm{Fr})^{\mathrm{b}} \\
\lambda_{\mathrm{s}}=\mathrm{K}(\mathrm{m} *)^{\mathrm{a}}(\mathrm{Fr})^{\mathrm{b}}\left(\rho / \rho_{\mathrm{s}}\right)^{\mathrm{c}}\left(\mathrm{d}_{\mathrm{s}} / \mathrm{D}\right)^{\mathrm{d}}
\end{gathered}
$$

These models have shown good results when applied to the researchers' own data. However, recent investigations by the authors (Mallick and Wypych 2008 2010) to examine the scale-up accuracy and stability of these existing model formats by comparing the predicted conveying characteristics against experimental data have shown that they generally provide inaccuracy under scale-up conditions of pipeline length and/ or diameter (e.g., overprediction by a factor of 2; Mallick 2010). This indicates that the existing modeling format and/ or parameter groupings, Equations (1)-(3), may be inadequate to properly describe the fluidized dense-phase flow phenomena. This may be caused by either or both of the following:

a. Equation (1): The basic assumption of treating air and solids phases separately may be inappropriate for fluidized 
dense-phase pneumatic conveying of fine powders considering the physical nature of the highly turbulent nature of the powder-air mixture.

b. Equations (2) and (3): the selected parameters groupings may be inappropriate and/or insufficient number of variables to describe the dense-phase flow mechanisms of fine powders.

Addressing the aforesaid point (a), a new approach of modeling has been employed by some researchers in recent years (Datta and Ratnayake 2003, 2005; Ratnayake and Datta 2007), where the solids-air mixture has been considered as a single phase (instead of treating solids and air separately). The total pressure drop due to solids-air mixture was represented using a combined "pressure drop coefficient" (K) and the concept of suspension density, as given by Equations (4) and (5).

$$
\begin{gathered}
\Delta \mathrm{P}=\mathrm{K} \rho_{\text {sus }} \mathrm{L} / \mathrm{DV}_{\text {entry }}^{2} / 2 \\
\rho_{\text {sus }}=\left(\mathrm{M}_{\mathrm{s}}+\mathrm{M}_{\mathrm{f}}\right) /\left(\mathrm{v}_{\mathrm{s}}+\mathrm{v}_{\mathrm{f}}\right)
\end{gathered}
$$

Barite $\left(\rho_{\mathrm{s}}: 4200 \mathrm{~kg} / \mathrm{m}^{3}\right.$; "mean particle size": $\left.12 \mu \mathrm{m}\right)$ and cement $\left(\rho_{\mathrm{s}}: 3100 \mathrm{~kg} / \mathrm{m}^{3}\right.$; "mean particle size": $\left.15.5 \mu \mathrm{m}\right)$ were conveyed through three test rigs: $\mathrm{L}=75 \mathrm{~m}, \mathrm{D}=80 \mathrm{~mm}$; $\mathrm{L}=66 \mathrm{~m}, \mathrm{D}=100 ; \mathrm{L}=68 \mathrm{~m}, \mathrm{D}=125 \mathrm{~m}$. Using pressure drop values recorded by the several pressure transmitters installed along the horizontal and vertical sections, $\mathrm{K}$ values were obtained for all the tests. The distances between two consecutive transmitters were kept limited to within $3 \mathrm{~m}$. It is to be noted that because of the considerable fluctuation in the pressure signal of a solids-gas system, it may be quite difficult to obtain an accurate estimate of pressure differential between two pressure transmitters when they are separated by such a relatively small distance. The plots of $\mathrm{K}$ versus (air velocity) ${ }^{2}$ values showed that $\mathrm{K}$ factor becomes highly sensitive to changes in (air velocity) $)^{2}$ when the value of (air velocity) ${ }^{2}$ is small (e.g., a sharp increase in $\mathrm{K}$, even with a small decrease in (air velocity) ${ }^{2}$ ). To address the aforesaid point (b), the work of Bradley (1990) is to be considered. Bradley (1990) mentioned that suspension density might be a better representative of flow characteristics compared to the popular use of $\mathrm{m}^{*}$. He found it logical to think that the "controlling influences on the regime of flow of solids in a pipe should be air velocity and the extent to which the pipe is filled, rather than a simple mass ratio." It is to be noted that the suspension density term defined by Bradley (1990) is different to the representation of (Datta and Ratnayake 2003, 2005; Ratnayake and Datta 2007) and is given by Equation (6).

$$
\rho_{\text {sus }}=\mathrm{m}_{\mathrm{s}} /(\mathrm{AV})
$$

A comparative study on the accuracy and stability of models developed using the two aforesaid definitions of suspension density has not been conducted so far for the scale-up conditions of pipe diameter and length. The objectives of the present work are to:

i. develop pressure drop models using both formats of suspension density (Equations (5) and (6)) using steady-state straight pipe data of conveying fly ash and electrostatic precipitator (ESP) dust;

ii. using the developed models: predict total pipeline pressure drop for larger and longer pipes (using appropriate bend model), compare the predictions obtained using the two models having different definitions of suspension density, viz., Equations (5) and (6); and compare them with respect to experimental data to evaluate their scaleup accuracy and stability.

\section{Experimental Setup}

Test data from fly ash and ESP dust were used in this study. Table 1 lists some physical properties of these products:

Australian power station fly ash and ESP dust were conveyed over a wide range of flow conditions (from diluteto fluidized dense-phase) through various pipelines, such as $69 \mathrm{~mm} \quad$ I.D. $\times 168 \mathrm{~m}, 105 \mathrm{~mm} \quad$ I.D. $\times 168 \mathrm{~m}$ and $69 \mathrm{~mm}$ I.D. $\times 554 \mathrm{~m}$ mild steel pipeline. A typical schematic of the test set up used is shown in Figure 1. As per Geldart (1973) and Dixon (1976), fly ash and ESP dust were group A and C type materials, respectively, indicating theoretically more cohesive tendency for ESP dust. However, both the materials were able to be conveyed in fluidized dense-phase mode. The $69 \mathrm{~mm}$ I.D. $\times 168 \mathrm{~m}$ long pipeline included $7 \mathrm{~m}$ vertical lift, five $1 \mathrm{~m}$ radius $90^{\circ}$ bends and $150 \mathrm{~mm}$ N.B. tee-bend connecting the end of the pipeline to the feed bin. For fly ash, static pressure measurement points, such as $\mathrm{P} 8, \mathrm{P} 9, \mathrm{P} 10, \mathrm{P} 11$, and $\mathrm{P} 12$, were employed along all the pipes. The P8 tapping location was used for total pipeline pressure drop. P9-P10 and P11-P12 tapping points were installed towards the beginning and end of pipe, respectively. For ESP dust, static pressure measurements were only installed at P9 and P10 locations of the $69 \mathrm{~mm}$ I.D. $\times 554 \mathrm{~m}$ pipe from where "straight pipe" data were obtained for modeling purpose. $\mathrm{A} 6 \mathrm{~m}^{3}$ receiving bin with insertable pulse-jet dust filter was provided. All other necessary instrumentation for data recording and analysis were provided. A portable PC-compatible data acquisition system (Datataker 800 or DT800 of Data Electronics, Australia) was used. Spigotted flanges were employed to ensure smooth internal surfaces at each pipe-pipe and pipebend connection.

\section{Modeling Straight Pipe Pressure Drop Using Suspension Density}

For the subsequent portion of this work, suspension density as defined by (Datta and Ratnayake 2003, 2005; Ratnayake and Datta 2007) will be referred to as format 1 and the expression for pressure drop is as given in Equation (4). suspension density as defined by Bradley (1990) will be

Table 1. Physical properties of the test products

\begin{tabular}{lccc}
\hline Product & $\rho_{\mathrm{s}}(\mathrm{kg} / \mathrm{m} 3)$ & $\rho_{\mathrm{b} 1}(\mathrm{~kg} / \mathrm{m} 3)$ & $\mathrm{d}_{50}{ }^{*}(\mu \mathrm{m})$ \\
\hline Fly ash & 2300 & 700 & 30 \\
ESP dust & 3637 & 610 & 7 \\
\hline
\end{tabular}

${ }^{*} \mathrm{~d}_{50}$ : median particle size (measured by laser diffraction analyzer). 


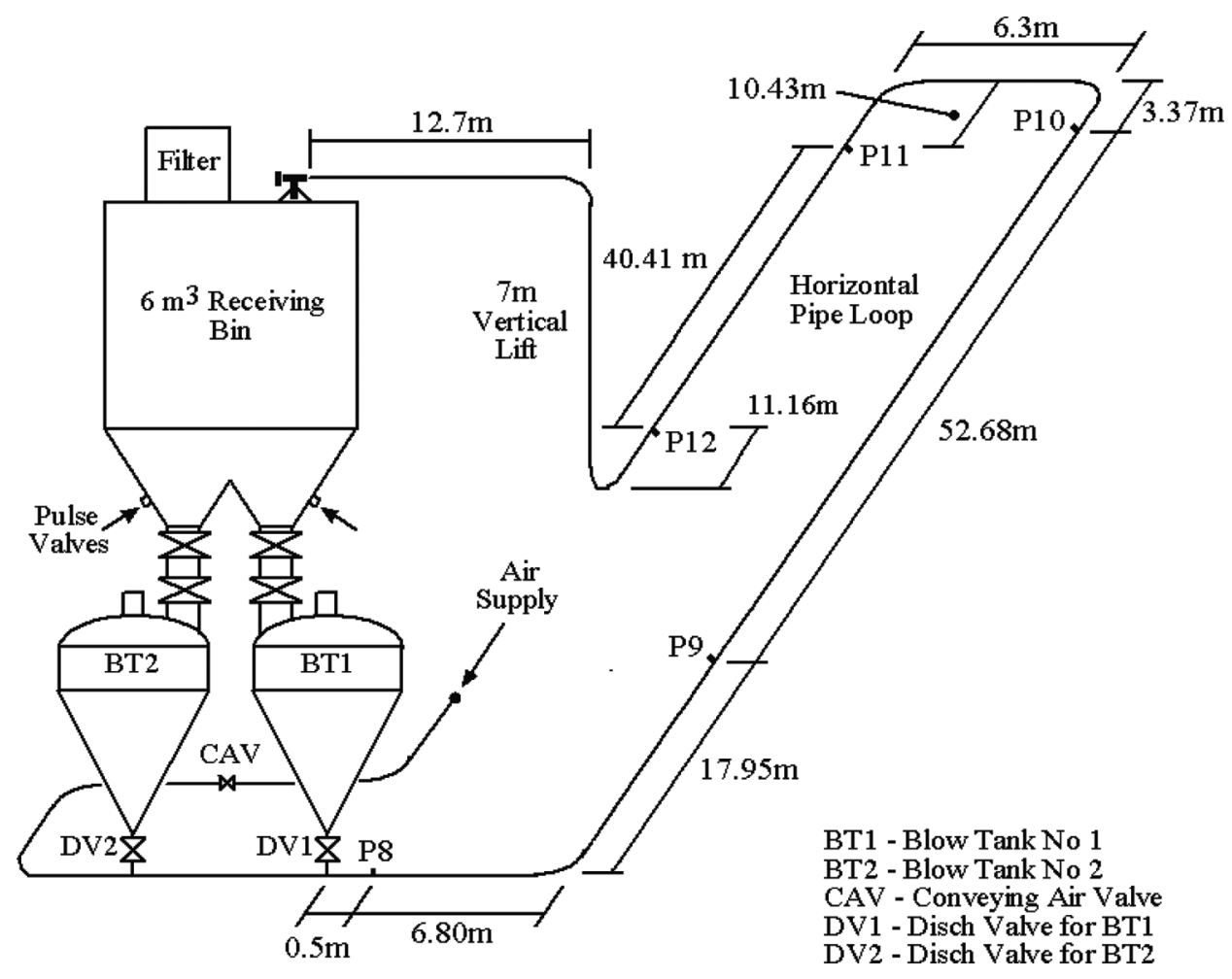

Fig. 1. Layout of the $69 \mathrm{~mm}$ I.D. $\times 168 \mathrm{~m}$ test rig.

referred to as format 2 and Equation (1) will be used as the expression for pressure drop.

\subsection{Fly Ash}

Using the steady-state pressure drop data of conveying fly ash between the static tapping points (P9 and P10) and (P11 and P12) of the $69 \mathrm{~mm}$ I.D. $\times 168 \mathrm{~m}$ test rig for a wide range of flow conditions (fluidized dense- to dilute-phase), the following models (Equations (7)-(10)) were derived by least square method. The range of average air velocities for the straight pipe sections were $3-14$ and $4-16 \mathrm{~m} / \mathrm{s}$ for P9-P10 and P11-P12, respectively, for 19,14 , and $9 \mathrm{t} / \mathrm{h}$ of solids flow rates.

Based on P9-P10 data, format 1:

$$
\mathrm{K}=0.1835\left(\mathrm{~V}_{\text {entry }}^{2}\right)^{-0.66}
$$

Based on P9-P10 data, format 2:

$$
\lambda_{\mathrm{s}}=\left(\rho_{\text {sus (format 2) }}\right)^{-0.26}(\mathrm{~V})^{-1.58}
$$

Based on P11-P12 data, format 1:

$$
\mathrm{K}=0.1373\left(\mathrm{~V}_{\text {entry }}^{2}\right)^{-0.60}
$$

Based on P11-P12 data, format 2:

$$
\lambda_{\mathrm{s}}=\left(\rho_{\text {sus (format 2) }}\right)^{-0.28}(\mathrm{~V})^{-1.55}
$$

The $R^{2}$ values for format 1 are 0.94 and 0.96 (for Equations (7) and (9), respectively) and for format 2 are 0.99 (for both Equations (8) and (100). The straight pipe conveying characteristics for P9-P10 and P11-P12 provided in Mallick (2010) showed that pressure drop per unit length from P11-P12 tapping points are higher than P9-P10 that were obtained for the same mass flow rates of solids and air.

\subsection{ESP Dust}

Using the steady-state pressure drop data of conveying ESP dust between the static tapping points (P9 and P10) of the $69 \mathrm{~mm}$ I.D. $\times 554 \mathrm{~m}$ test rig for a wide range of flow conditions (fluidized dense- to dilute-phase), the following models were derived by least square method (Equations (11) and 12)). The range of average air velocities for the straight pipe sections were $3-12 \mathrm{~m} / \mathrm{s}$ for 12,10 , and $8 \mathrm{t} / \mathrm{h}$ of solids flow rates.

$$
\begin{aligned}
& \text { format } 1: \mathrm{K}=0.468\left(\mathrm{~V}_{\text {entry }}^{2}\right)^{-0.754} \\
& \text { format } 2: \lambda_{\mathrm{s}}=\left(\rho_{\text {sus (format 2) }}\right)^{-0.12}(\mathrm{~V})^{-1.62}
\end{aligned}
$$

The $R^{2}$ values for Equations (11) and (12)are 0.97 and 0.99 , respectively.

Comparing Equations (7) and (9), it is observed that in format 1 , even for the same product (fly ash), the derived models are appreciably different, that is, the values of constants and exponents of $\mathrm{V}$ are different depending on the location of pressure tapping: (P9-P10) or (P11-P12). However for format 2, the models (Equations (8) and (10)) are quite similar for the same product (fly ash) and different tapping location (i.e., the values of constants and exponents of suspension density and air velocity are very close to each other). Comparing Equations (7) and (11), it is observed that, 
in format 1 , the models are different (as expected), that is, the values of constants and exponents of $\mathrm{V}$ are different for different products (fly ash and ESP dust). Similar observations are noticed for format 2, comparing Equations (8) and (12). Comparing Equations (7), (9), and (11) (format 1 ), the values of the constant term and absolute values of the exponents of $V_{\text {entry }}^{2}$ are considerably higher for ESP dust than fly ash (indicating a stronger influence of $V_{\text {entry }}$ on the derived model for ESP dust). Comparing Equations (8), (10), and (12) (format 2), the absolute values of suspension densities are significantly higher for fly ash than ESP dust (indicating a stronger influence of suspension density on the derived model for fly ash).

\section{Scale-Up Evaluation of Models}

\section{$4.1 \mathrm{Fly}$ Ash}

The models developed in formats 1 and 2 for fly ash using P9-P10 data, that is, Equations (7) and (8), were evaluated for scale-up accuracy and stability by using them to predict the total pipeline drop for the larger and longer pipelines (viz. $69 \mathrm{~mm}$ I.D. $\times 168 \mathrm{~m}, 105 \mathrm{~mm}$ I.D. $\times 168 \mathrm{~m}$ and $69 \mathrm{~mm}$ I.D. $\times 554 \mathrm{~m}$ ) for various solids flow rates and by comparing the predicted and experimental PCC. The Chambers and Marcus (1986) model was used to estimate the losses due to the bends. The results are shown in Figures 2-4. The Chambers and Marcus (1986) bend model predicted pressure drop through bends as approximately $10 \%$ of the total pipeline pressure drop values (detail analysis is provided in Mallick 2010). Hence, estimated bend losses, on their own, do not influence the quality of prediction for total pipeline pressure loss in dense-phase. Therefore, if there are considerable differences between predicted and experimental total pipeline pressure losses, those must be due to inaccurate models for straight pipe solids pressure drop. Table A1 in the appendix lists the ratio of the amount of over/under-prediction (using different models and pipelines) to the respective experimental PCC of all the evaluation work carried out this paper. The ratios are provided in percentages. Percentages are provided only for dense-phase region, as the contribution of straight pipe

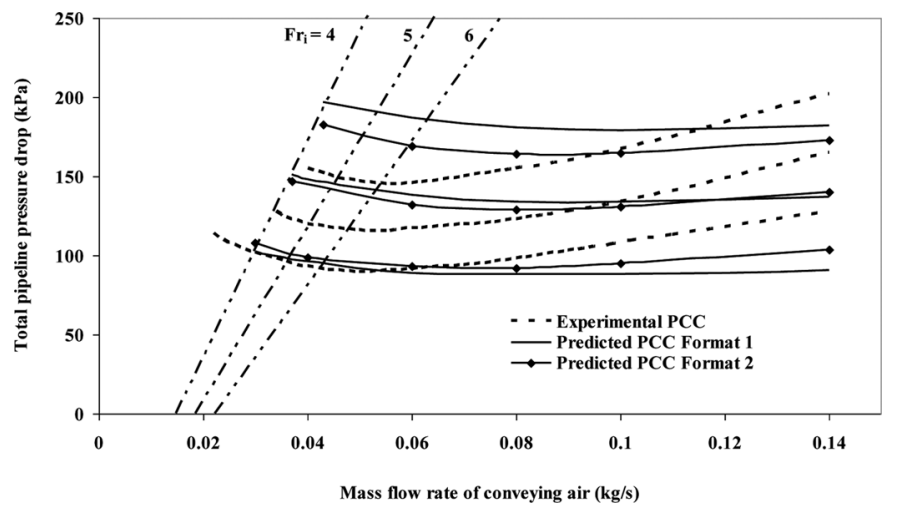

Fig. 2. Experimental versus predicted PCC for fly ash and $69 \mathrm{~mm}$ I.D. $\times 168 \mathrm{~m}$ long pipe using Equations (7) and (8) (top line$\mathrm{s}: 19 \mathrm{t} / \mathrm{h}$, middle lines: $14 \mathrm{t} / \mathrm{h}$, bottom lines: $9 \mathrm{t} / \mathrm{h})$.

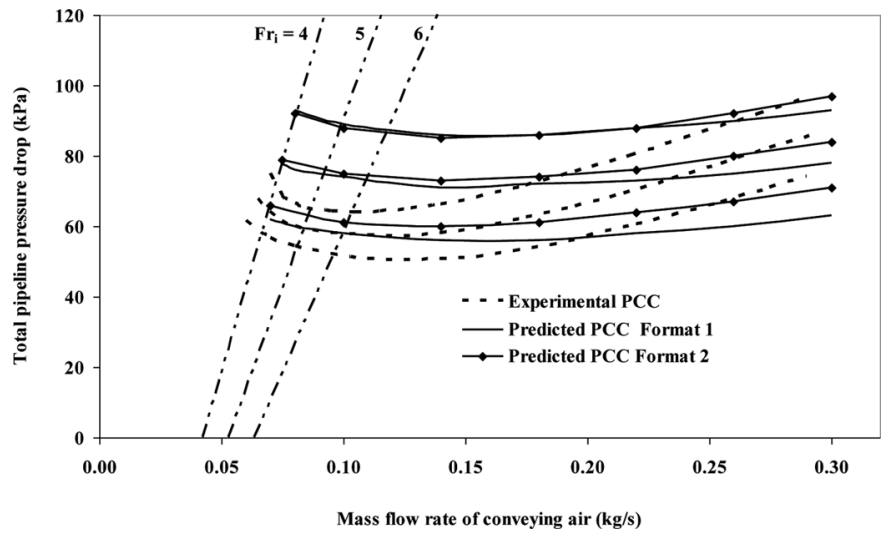

Fig. 3. Experimental versus predicted PCC for fly ash and $105 \mathrm{~mm}$ I.D. $\times 168 \mathrm{~m}$ long pipe using Equations (7) and (8) (top lines: $28 \mathrm{t} / \mathrm{h}$, middle lines: $23 \mathrm{t} / \mathrm{h}$, bottom lines: $18 \mathrm{t} / \mathrm{h}$ ).

losses (the aim is to find the accuracy of prediction of this) in the predicted total pipeline pressure drop values are relatively more in dense-phase than in dilute. The overall percentages are obtained by averaging individual percentages for each solids flow rates.

The results show that for the $69 \mathrm{~mm}$ I.D. $\times 168 \mathrm{~m}$ long pipe, the 19 and $14 \mathrm{t} / \mathrm{h}$ lines in both formats 1 and 2 provide some over-prediction in the dense-phase region (low velocity zone), whereas the $9 \mathrm{t} / \mathrm{h}$ line provide good prediction for both formats. All the predictions show under-prediction in dilute-phase (higher velocity zone). Formats 1 and 2 result in different PCC for $19 \mathrm{t} / \mathrm{h}$ (format 2 providing relatively better prediction in dense-phase). However, both formats provide relatively similar predictions for 14 and $9 \mathrm{t} / \mathrm{h}$ in dense-phase, although the predicted PCC for formats 1 and 2 begin to separate toward the dilute-phase region. For the $105 \mathrm{~mm}$ I.D. $\times 168 \mathrm{~m}$ long pipe, both the formats provide over-prediction in dense-phase region (especially for the 28 and $23 \mathrm{t} / \mathrm{h}$ lines). However, for this diameter scale-up, the accuracy of prediction using the suspension density methods (formats 1 and 2) is relatively better than that obtained

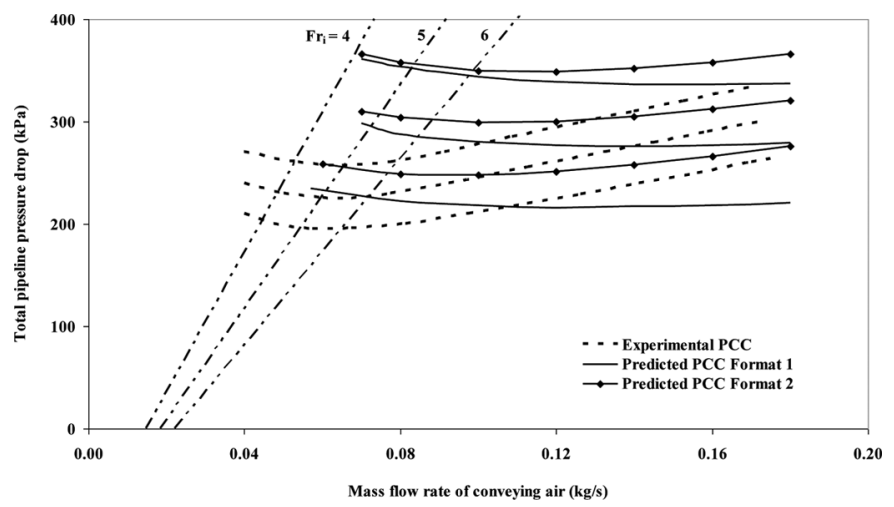

Fig. 4. Experimental versus predicted PCC for fly ash and $69 \mathrm{~mm}$ I.D. $\times 554 \mathrm{~m}$ long pipe using Equations (7) and (8) (top lines: $11 \mathrm{t} / \mathrm{h}$, middle lines: $9 \mathrm{t} / \mathrm{h}$, bottom lines: $7 \mathrm{t} / \mathrm{h}$ ). 
by using the solid loading ratio and Froude number based modeling approach (Mallick and Wypych 2010). For the significant length scale-up condition (Figure 4), the higher solid flow lines $(11$ and $9 \mathrm{t} / \mathrm{h}$ ) provide considerable overprediction in dense-phase. Relatively better predictions are obtained for the $7 \mathrm{t} / \mathrm{h}$ line in dense-phase. However, the $7 \mathrm{t} / \mathrm{h}$ line results in considerable under-prediction in dilutephase. For the $11 \mathrm{t} / \mathrm{h}$ solids flow rate, formats 1 and 2 provide similar predictions in dense-phase, whereas the PCC for the different formats diverge in the dilute-phase region. Prediction using the model developed with the P11-P12 data in format 1 for fly ash (Equation (9)) is provided in Figures A1-A3 in the appendix. Since the model given by Equation (10) is very similar to Equation (8) (for which predictions are shown in Figures 2-4), prediction with Equation (10) is not superimposed in Figures A1-A3. In Figure A1, the $19 \mathrm{t} / \mathrm{h}$ PCC show some over-prediction in dense-phase, whereas the other solid flow lines provide slightly better results in dense-phase. All the predicted PCC show underprediction in dilute-phase. For the case of diameter scale-up $(105 \mathrm{~mm}$ I.D. $\times 168 \mathrm{~m}$ long pipe, Figure A2), the 28 and $23 \mathrm{t} / \mathrm{h}$ lines provide some over-prediction in dense-phase, whereas the $18 \mathrm{t} / \mathrm{h}$ line provides reasonably good prediction in dense-phase. The 23 and $18 \mathrm{t} / \mathrm{h}$ PCC show under-prediction in dilute-phase. For the case of significant length scale-up (69 mm I.D. $\times 554 \mathrm{~m}$ long pipe, Figure A3), the 11 and $9 \mathrm{t} / \mathrm{h}$ lines provides considerable over-prediction in dense-phase, whereas the $7 \mathrm{t} / \mathrm{h}$ line provides reasonably good prediction in dense-phase. The 9 and $7 \mathrm{t} / \mathrm{h}$ PCC show under-prediction in dilute-phase. All the predicted PCC in Figures A1-A3 show a flat trend, whereas the experimental PCC are rather U-shaped. In summary, the suspension density based models have generally resulted in better predictions for fly ash compared to the power function based models (using the solids loading ratio and Froude number as dimensionless parameters) previously developed the authors (Mallick and Wypych 2010).

\subsection{ESP Dust}

The models developed in formats 1 and 2 for ESP dust using P9-P10 data (i.e., Equations (11) and (12)) were evaluated for scale-up accuracy and stability by using them to predict the total pipeline pressure drop for the larger and longer pipelines (viz. $69 \mathrm{~mm}$ I.D. $\times 168 \mathrm{~m}$; $105 \mathrm{~mm}$ I.D. $\times 168 \mathrm{~m}$; and $69 \mathrm{~mm}$ I.D. $\times 554 \mathrm{~m}$ ) for various solids flow rates and by comparing the predicted and experimental PCC. The Chambers and Marcus (1986) model was used again to estimate the losses due to the bends. The results are shown in Figures 5-7.

Figure 5 and 6 show that both the formats provide fairly good and similar predictions in dense-phase (with slight over- and under-predictions for the highest and lowest mass flow rate lines, respectively). The PCC generally show a tendency of under-prediction towards dilute-phase. For the case of significant length scale-up (Figure 7), the $10 \mathrm{t} / \mathrm{h}$ line provides considerable over-prediction, however relatively better predictions are obtained (though still with some

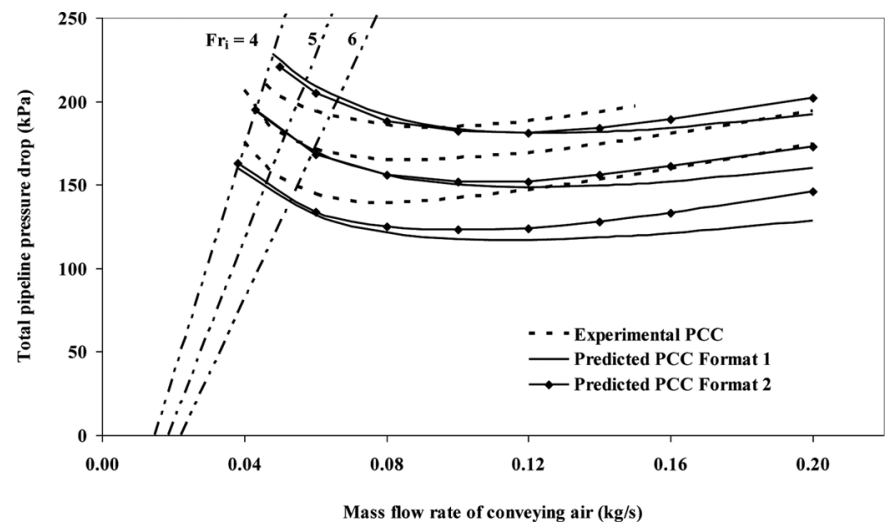

Fig. 5. Experimental versus predicted PCC for ESP dust and $69 \mathrm{~mm}$ I.D. $\times 168 \mathrm{~m}$ long pipe using Equations (11) and (12) (top lines: $12 \mathrm{t} / \mathrm{h}$, middle lines: $10 \mathrm{t} / \mathrm{h}$, bottom lines: $8 \mathrm{t} / \mathrm{h}$ ).

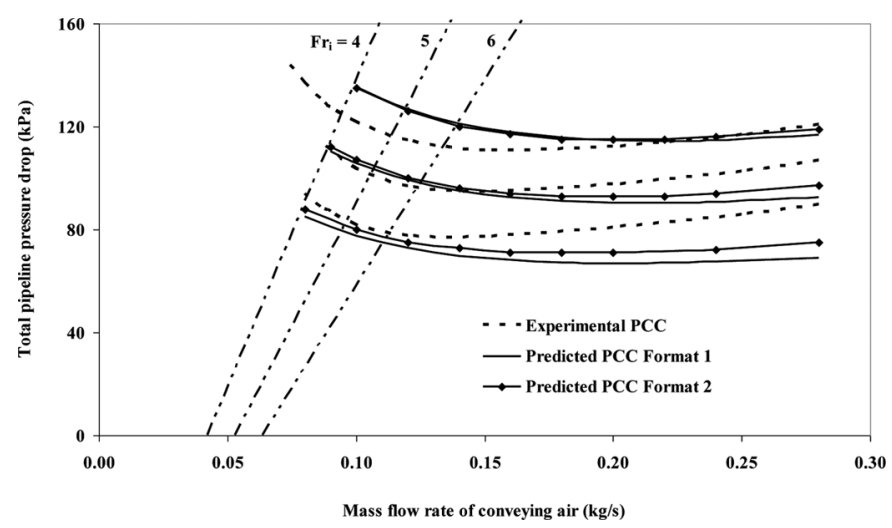

Fig. 6. Experimental versus predicted PCC for ESP dust and 105 I.D. $\times 168 \mathrm{~m}$ long pipe using Equations (11) and (12) (top lines: $25 \mathrm{t} / \mathrm{h}$, middle lines: $20 \mathrm{t} / \mathrm{h}$, bottom lines: $15 \mathrm{t} / \mathrm{h}$ ).

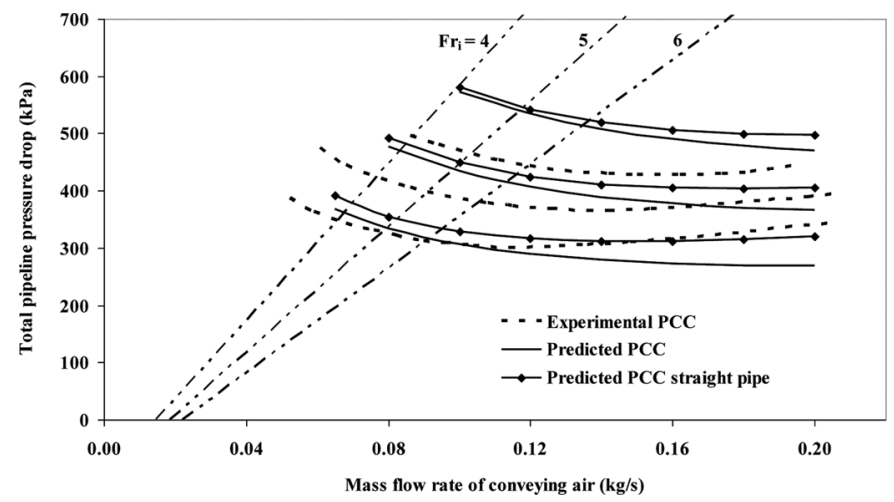

Fig. 7. Experimental versus predicted PCC for ESP dust and $69 \mathrm{~mm}$ I.D. $\times 554 \mathrm{~m}$ long pipe using Equations (11) and (12) (top lines: $10 \mathrm{t} / \mathrm{h}$, middle lines: $8 \mathrm{t} / \mathrm{h}$, bottom lines: $6 \mathrm{t} / \mathrm{h}$ ).

over-prediction) for 8 and $6 \mathrm{t} / \mathrm{h}$. Again, both formats resulted in fairly similar predictions in dense-phase. The $6 \mathrm{t} / \mathrm{h}$ solid flow line shows considerable under-prediction in 
dilute-phase. The accuracy of prediction using the suspension density methods (formats 1 and 2) are relatively better than that obtained by using the solid loading ratio and Froude number based modeling approach (Mallick and Wypych 2010) that could provide inaccuracy for prediction of total pipeline pressure by a factor of 2 (under or overprediction).

\section{Conclusions}

Under scale-up conditions, both formats of the suspension density based models provided similar predictions in dense-phase for ESP dust. However, the formats resulted in considerably different predictions for some cases of fly ash (dilute-phase region for Figure 4 for 11,9 , and $7 \mathrm{t} / \mathrm{h}$ solids flow rates). For both the formats and products, the models have a general tendency of under-prediction in the dilute-phase region. Based on the fly ash data, it was found that the models generated in format 1 depend on the location of tapping point, whereas the models derived in format 2 from different tapping point locations are quite similar to each other. Overall it was found that the suspension density and air velocity based models generally provide better scale-up prediction than the solids loading ratio and Froude number models of the conventional approach. Further research is required to better understand the relevant flow mechanisms and to validate the modeling method for a wider range of products and scale-up pipelines.

\section{Nomenclature}

$\begin{array}{ll}\mathrm{A} & \text { cross-sectional area of pipe }\left[\mathrm{m}^{2}\right] \\ \mathrm{D} & \text { internal diameter of pipe }[\mathrm{m}] \\ \mathrm{Fr} & \text { Froude Number based on gas } \\ & \text { velocity }=\mathrm{V} / \sqrt{\mathrm{gD}} \\ \mathrm{g} & \text { acceleration due to gravity }\left[\mathrm{m} / \mathrm{s}^{2}\right] \\ \mathrm{L} & \text { length of pipe section }[\mathrm{m}] \\ \mathrm{K} & \text { pressure drop coefficient } \\ \mathrm{m}_{\mathrm{f}} & \text { mass flow rate of air }[\mathrm{kg} / \mathrm{s}] \\ \mathrm{m}_{\mathrm{s}} & \text { mass flow rate of solids }[\mathrm{kg} / \mathrm{s}] \\ \mathrm{m}^{*} & \text { solid loading ratio }=\mathrm{m}_{\mathrm{s}} / \mathrm{m}_{\mathrm{f}} \\ \mathrm{M}_{\mathrm{f}} & \text { mass of air in a control volume }[\mathrm{kg}] \\ \mathrm{M}_{\mathrm{s}} & \text { mass of solids in a control volume }[\mathrm{kg}] \\ \mathrm{PCC} & \text { pneumatic conveying characteristics } \\ \Delta \mathrm{P} & \text { pressure drop due to solids and air }[\mathrm{Pa}] \\ \rho_{\mathrm{sus}} & \text { suspension density }\left[\mathrm{kg} / \mathrm{m}^{3}\right]-\text { different } \\ & \text { definitions for formats } 1 \text { and } 2 \\ \mathrm{~V}_{\mathrm{s}} & \text { volume of solids in a control volume }\left[\mathrm{m}^{3}\right] \\ \mathrm{V} & \text { superficial average air velocity for the test } \\ & \text { section }[\mathrm{m} / \mathrm{s}] \\ \mathrm{v}_{\mathrm{f}} & \text { volume of air in a control volume }\left[\mathrm{m}^{3}\right] \\ \rho & \text { density of air }\left[\mathrm{kg} / \mathrm{m}^{3}\right] \\ \rho_{\mathrm{bl}} & \text { loose-poured bulk density }\left[\mathrm{kg} / \mathrm{m}^{3}\right] \\ \left.\rho_{\mathrm{s}}\right] & \text { particle density }\left[\mathrm{kg} / \mathrm{m}^{3}\right] \\ \lambda_{\mathrm{f}} & \text { friction factor due to air only } \\ \lambda_{\mathrm{s}} & \text { solid friction factor for straight pipe }\end{array}$

\section{Subscripts}

i,entry value at the entry of pipe v vertical

\section{Abbreviations}

$\begin{array}{ll}\text { ESP } & \text { electro static precipitator } \\ \text { I.D. } & \text { internal diameter of pipe } \\ \text { R } & \text { correlation coefficient }\end{array}$

\section{References}

Barth, W. 1958. Strömungsvorgänge beim Transport von Festteilchen und Flüssigkeitsteilchen in Gasen. Chemie Ingenieur Technik 30 (3): 171-180.

Bradley, M. S. A. 1990. Prediction of pressure losses in pneumatic conveying pipelines. PhD dissertation, Thames Polytechnic.

Chambers, A. J., and R. D. Marcus. 1986. Pneumatic conveying calculations. In Proceedings of 2nd International Conference on Bulk Materials Storage and Transportation 49-52. Wollongong, Australia, July 7-9.

Datta, B. K., and C. Ratnayake. 2003. A simple technique for scaling up pneumatic conveying systems. Particulate Science and Technology 21: 227-236.

Datta, B. K., and C. Ratnayake. 2005. A possible scaling-up technique for dense phase pneumatic conveying. Particulate Science and Technology 23: 201-204.

Dixon, D. 1976. Brief communication: Particle velocities in vertical pneumatic conveying systems. International Journal of Multiphase Flow 2: 465-470.

Geldart, D. 1973. Types of gas fluidization. Powder Technology 7: 285-292.

Jones, M. G., and K. C. Williams. 2003. Solids friction factors for fluidized dense-phase conveying. Particulate Science and Technology 21: $45-56$.

Mallick, S. S. 2010. Modelling fluidised dense phase pneumatic conveying of powders. PhD dissertation, University of Wollongong.

Mallick, S. S., and P. W. Wypych. 2008. Investigation into modelling solids friction for dense-phase pneumatic conveying of powders. Bulk Solids and Powder-Science and Technology 3 (1): $1-14$.

Mallick, S. S., and P. W. Wypych. 2010. An investigation into modelling of solids friction for dense-phase pneumatic conveying of powders. Particulate Science and Technology 28: 51-66.

Pan, R. 1992. Improving scale-up procedures for the design of pneumatic conveying systems. PhD dissertation, University of Wollongong.

Pan, R., and P. W. Wypych. 1998. Dilute and dense phase pneumatic conveying of fly ash. In Proceedings of the 6th International Conference on Bulk Materials Storage and Transportation, 183-189. Wollongong, NSW, Australia, September, 28-30.

Ratnayake, C., and B. K. Datta. 2007. A unified scaling-up technique for pneumatic conveying systems. Particulate Science and Technology. 25: 289-302.

Weber, M. 1981. Principles of hydraulic and pneumatic conveying on pipes. Bulk Solids Handling 1: 57-63.

Williams, K. C., and M. G. Jones. 2004. Numerical model velocity profile of fluidised dense phase pneumatic conveying. In Proceedings of 8th International Conference on Bulk Materials Storage and Transportation, 354-358. Wollongong, NSW, Australia, July $5-8$. 


\section{Appendix}

Table A.1. Ratio of amount of over/under-prediction to the experimental PCC of the various scale-up evaluation results (Figures 2-7)

\begin{tabular}{lcc}
\hline $\begin{array}{l}\text { Figure } \\
\text { number. }\end{array}$ & $\begin{array}{l}\text { Percentage } \\
\text { (format 1) }\end{array}$ & $\begin{array}{r}\text { Percentage } \\
\text { (format 2) }\end{array}$ \\
\hline 2 & +25 & +12 \\
3 & +24 & +24 \\
4 & +35 & +35 \\
5 & +25 & +2 \\
6 & +2 & +5 \\
7 & +8 & +17 \\
\hline
\end{tabular}

Note: $(+)=$ over-prediction; $(-)=$ under-prediction.

Percentages are provided only for dense-phase region; percentages for different solids flow rates are calculated and averaged. The averaged percentage values are provided in the above table.

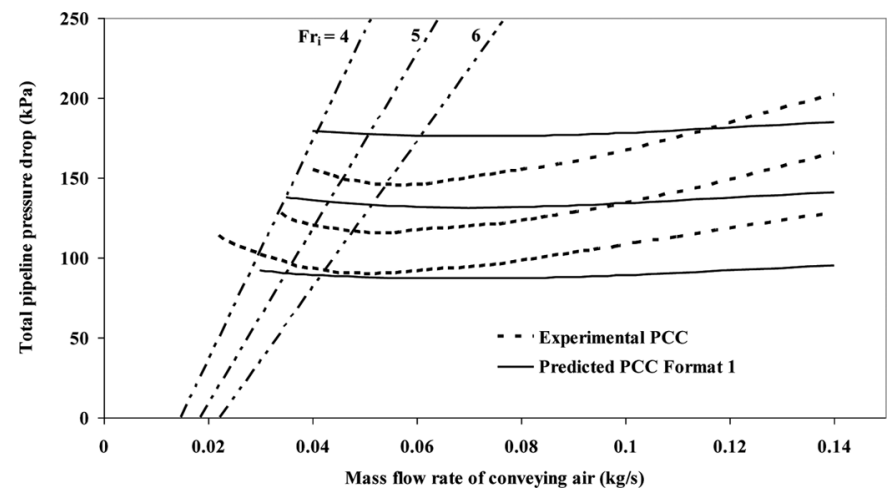

Fig. A1. Experimental versus predicted PCC for fly ash and $69 \mathrm{~mm}$ I.D. $\times 168 \mathrm{~m}$ long pipe using Equation 9 (top line$\mathrm{s}: 19 \mathrm{t} / \mathrm{h}$, middle lines: $14 \mathrm{t} / \mathrm{h}$, bottom lines: $9 \mathrm{t} / \mathrm{h}$ ).

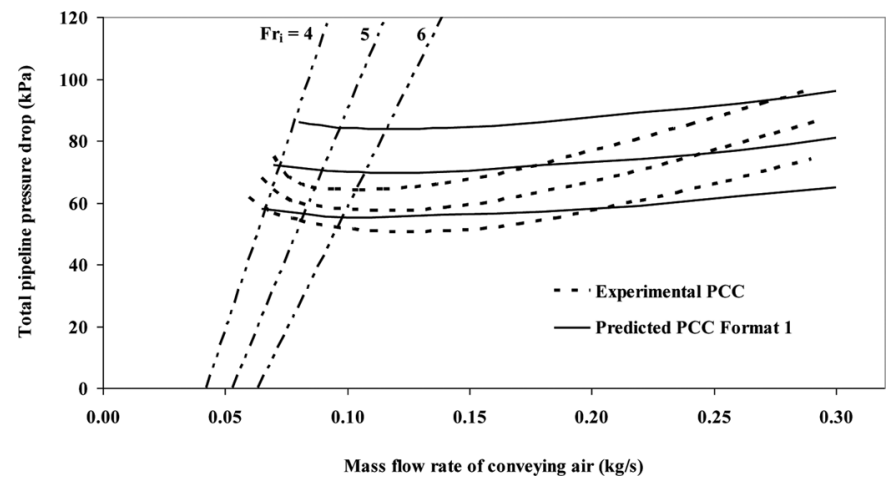

Fig. A2. Experimental versus predicted PCC for fly ash and $105 \mathrm{~mm}$ I.D. $\times 168 \mathrm{~m}$ long pipe using Equation 9 (top line$\mathrm{s}: 28 \mathrm{t} / \mathrm{h}$, middle lines: $23 \mathrm{t} / \mathrm{h}$, bottom lines: $18 \mathrm{t} / \mathrm{h}$ ).

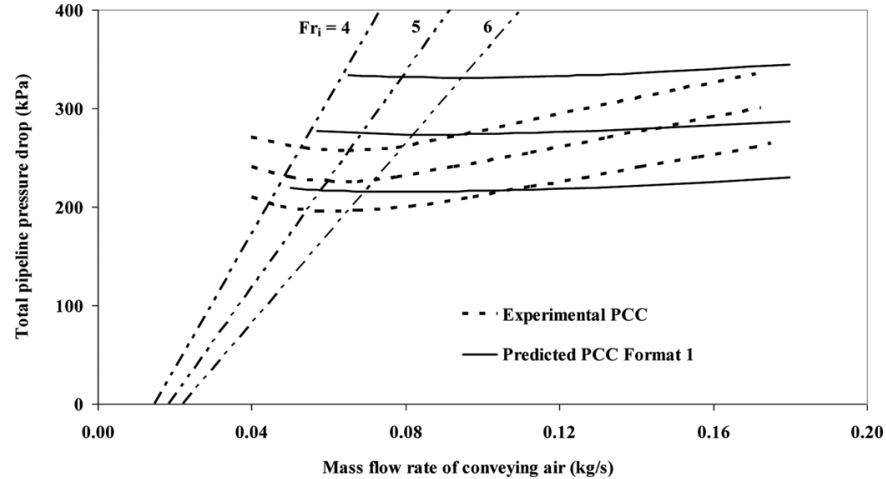

Fig. A3. Experimental versus predicted PCC for fly ash and $69 \mathrm{~mm}$ I.D. $\times 554 \mathrm{~m}$ long pipe using Equation 9 (top line$\mathrm{s}: 11 \mathrm{t} / \mathrm{h}$, middle lines: $9 \mathrm{t} / \mathrm{h}$, bottom lines: $7 \mathrm{t} / \mathrm{h}$ ).

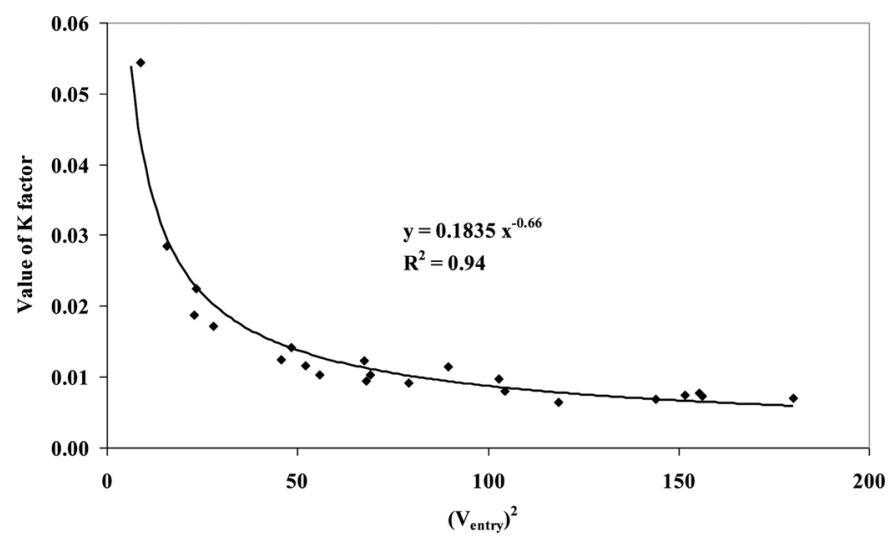

Fig. A4. $\mathrm{K}$ factor versus predicted $\left(\mathrm{V}_{\text {entry }}\right)^{2}$ for fly ash, P9-P10 data of $69 \mathrm{~mm}$ I.D. $\times 168 \mathrm{~m}$ long pipe.

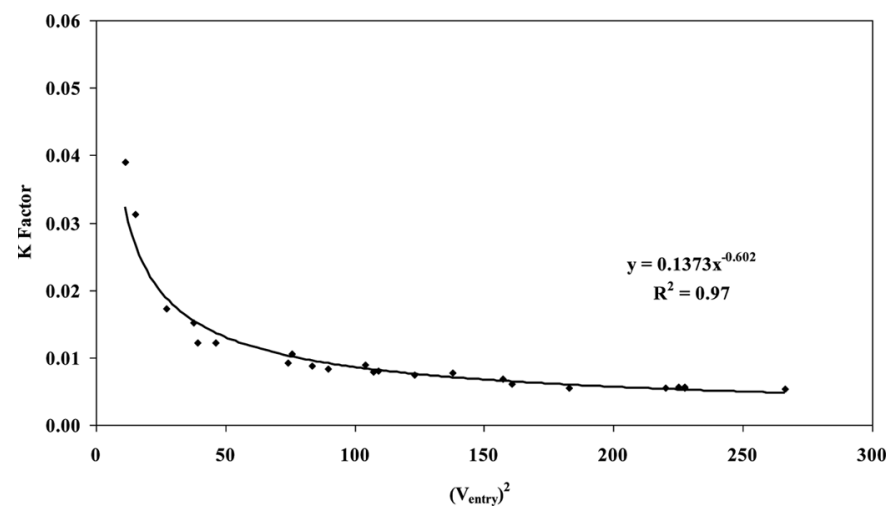

Fig. A5. $\mathrm{K}$ factor versus predicted $\left(\mathrm{V}_{\text {entry }}\right)^{2}$ for fly ash, P11-P12 data of $69 \mathrm{~mm}$ I.D. $\times 168 \mathrm{~m}$ long pipe. 


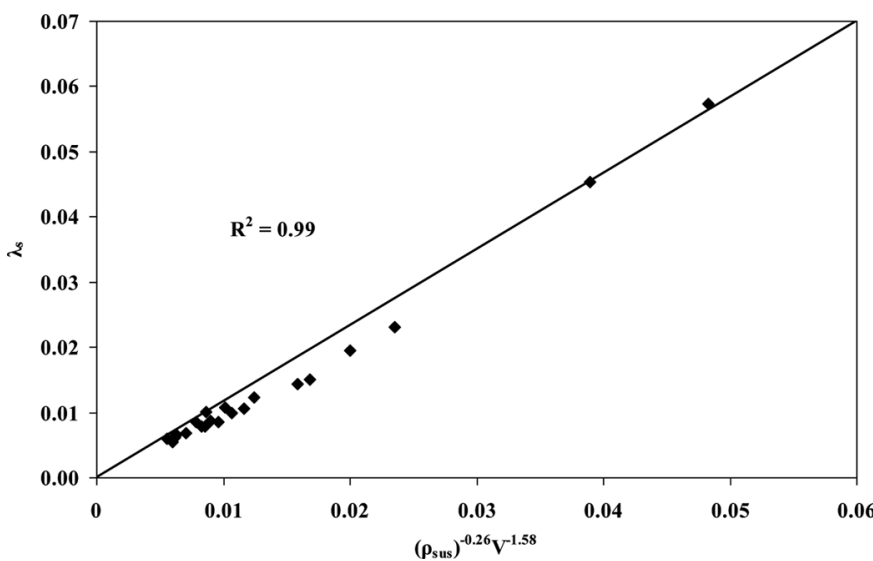

Fig. A6. Experimental $\lambda_{\mathrm{s}}$ versus predicted $\left(\rho_{\text {entry }}\right)^{-0.26}\left(\mathrm{~V}_{\text {entry }}\right)^{1.58}$ for fly ash, P9-P10 data of $69 \mathrm{~mm}$ I.D. $\times 168 \mathrm{~m}$ long pipe.

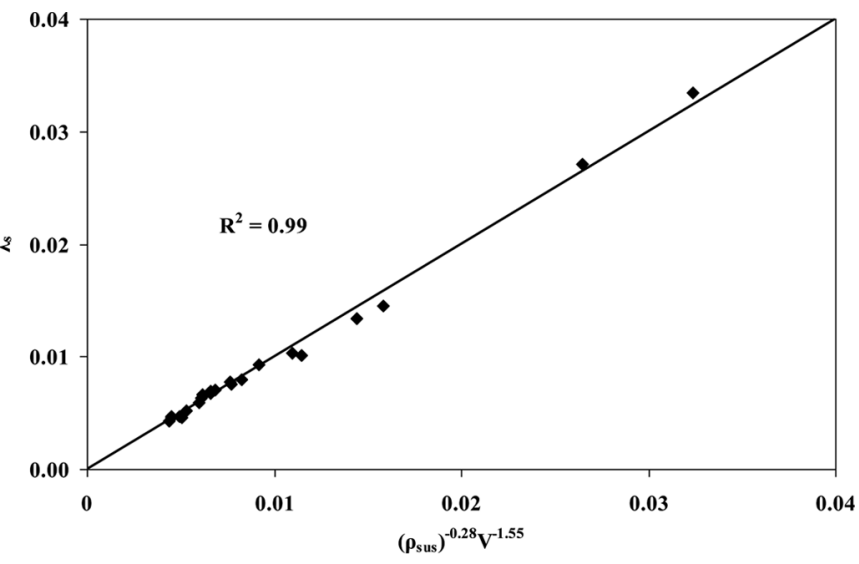

Fig. A7. Experimental $\lambda_{\mathrm{s}}$ versus predicted $\left(\rho_{\text {entry }}\right)^{-0.28}\left(\mathrm{~V}_{\text {entry }}\right)^{1.55}$ for fly ash, P11-P12 data of $69 \mathrm{~mm}$ I.D. $\times 168 \mathrm{~m}$ long pipe. 